\title{
Total Versus Subtotal Thyroidectomy for Benign Multinodular Goiter: Outcome and Complications
}

\author{
Mohamed Rifaat ${ }^{\mathrm{a}}$, Aly Saber ${ }^{\mathrm{b}, \mathrm{c}}$, Emad N Hokkam $^{\mathrm{a}}$
}

\begin{abstract}
Background: Thyroid gland diseases constitute the second most common endocrine disease following diabetes mellitus. Thyroidectomy is one of the most common frequent operations including bilateral subtotal thyroidectomy and total thyroidectomy. The aim of this study was to review and assess the complications with outcomes following total versus subtotal thyroidectomy.
\end{abstract}

Methods: A retrospective analytic study was conducted on 242 benign multinodular goiter (BMNG) patients who were divided according to surgical technique into two main groups T and ST. Group $\mathrm{T}$ patients were subjected to total thyroidectomy and those of group ST were subjected to subtotal thyroidectomy.

Results: No permanent or bilateral recurrent laryngeal nerve (RLN) injuries occurred for patients in both groups. Superior laryngeal nerve (SLN) and temporary RLN injuries were in two in six patients (5\%) in ST group and in seven patients in T group (5.8\%). No permanent hypoparathyroidism was seen in group ST patients but in one patient $(0.8 \%)$ of group $\mathrm{T}$; transient hypoparathyroidism occurred in two patients $(1.6 \%)$ in ST group and in one patient $(0.8 \%)$ in $\mathrm{T}$ group.

Conclusion: Total or subtotal thyroidectomy outcomes and complications are similar and depend on good and proper preoperative preparation and the use of a meticulous surgical technique.

Keywords: Thyroidectomy; Total; Subtotal; Complication

\section{Introduction}

The surgical technique is one of the important factors affect-

Manuscript accepted for publication June 12, 2014

${ }^{a}$ Faculty of Medicine, Suez Canal University, Egypt

${ }^{b}$ Port-Fouad General Hospital, Port-Fouad, Egypt

${ }^{\mathrm{c}}$ Corresponding Author: Aly Saber, Port-Fouad General Hospital, Port-

Fouad, Egypt. Email: alysaber54@gmail.com

doi: http://dx.doi.org/10.14740/jcs224w ing the outcome of thyroidectomy [1]. Primary thyroid disease, weight of dissected tissue and extent of surgical treatment are also points influencing patients' outcome [2]. In the past, most surgeons avoided dissections in close proximity to the recurrent laryngeal nerve (RLN) to prevent its injury. The identification and preservation of the RLN together with meticulous hemostasis and delicate technique are required to prevent nerve injury. Once found, the nerve with all the identified branches must be followed superiorly through the entire course, until it enters the larynx [3].

Total thyroidectomy has been accepted as current surgical therapy for benign and malignant thyroidal disorders $[4$, 5], but extensive resection might increase the risk of postoperative complications [6]. Subtotal thyroid resection in the case of benign goiter carries a high risk of recurrence. The relatively high rate of postoperative cancer findings also leads frequently to secondary completion thyroidectomy. Internationally therefore the paradigm has shifted from subtotal resection to extended or total thyroidectomy, which shifts the risk to the vocal cords and parathyroids, where as a rule complications are much worse than those to the thyroid [7].

RLN dysfunction and hypoparathyroidism are well-recognized important complications of thyroid surgery. Complication rates of thyroidectomy have a varying range for both RLN injury (0-14\%) and permanent hypoparathyroidism (1$11 \%$ ) [1]. Intensive effort should be spent to prevent these events, because they can be prevented with appropriate surgical technique during total thyroidectomy $[2,3,5]$.

The risk of complications after extended resection is not significantly higher than after classic subtotal resection without identification of the nerve and parathyroids [8-10]. The aim of this study was to review and assess the complications with outcomes following total versus subtotal thyroidectomy.

\section{Materials and Methods}

A total of 242 patients diagnosed to have bilateral BMNG were enrolled to this prospective analytic study conducted in Suez Canal University Hospital, Ismailia, Egypt and PortFouad General Hospital, Port-Fouad, Egypt from January 

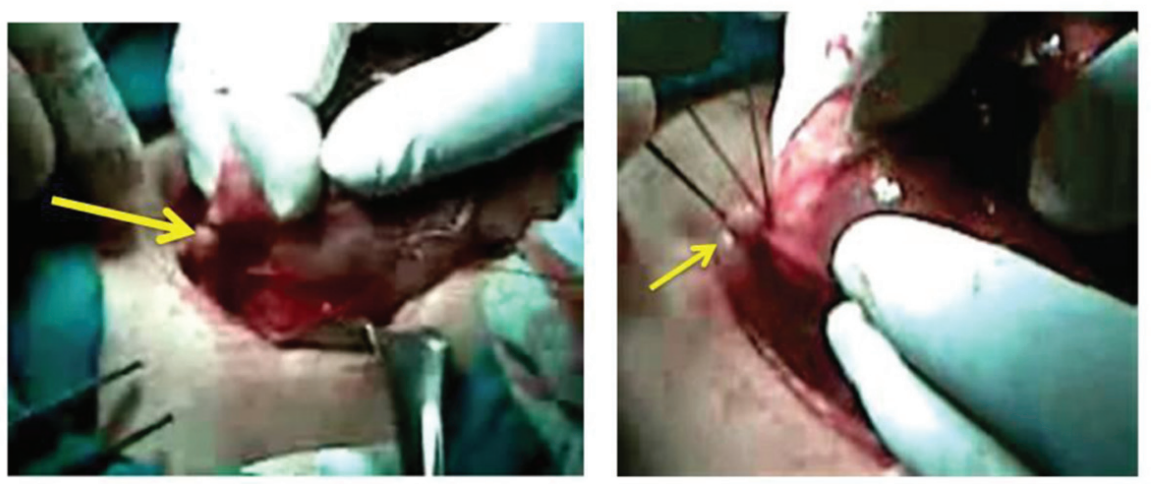

Figure 1. The superior thyroid artery indentified and dissected meticulously as close to the thyroid capsule as possible to avoid damaging the superior laryngeal nerve.

2005 to December 2012. Patients were subjected to primary thyroidectomy (total or subtotal) without previous neck surgery or radiotherapy; meanwhile, the indications of surgery in the present study were the compression symptoms and/ or huge neck swelling. All the patients data were collected such as demographic data (age at diagnosis, gender, occupation and residence), and presenting symptoms (dysphagia dyspnea, hoarseness, and others).

BMNG patients were divided according to surgical technique into two main groups T and ST. Group T patients were subjected to total thyroidectomy and those of group ST were subjected to subtotal thyroidectomy.

Randomization was performed prior to study commencement as follows: opaque envelopes were numbered sequentially from 1 to 242 . A computer-generated table of random numbers was used for group assignment; if the last digit of the random number was from 0 to 4 , assignment was to group A (total thyroidectomy (T group)), and if the last digit was from 5 to 9 , assignment was to group B (subtotal thyroidectomy (ST group)). The assignments were then

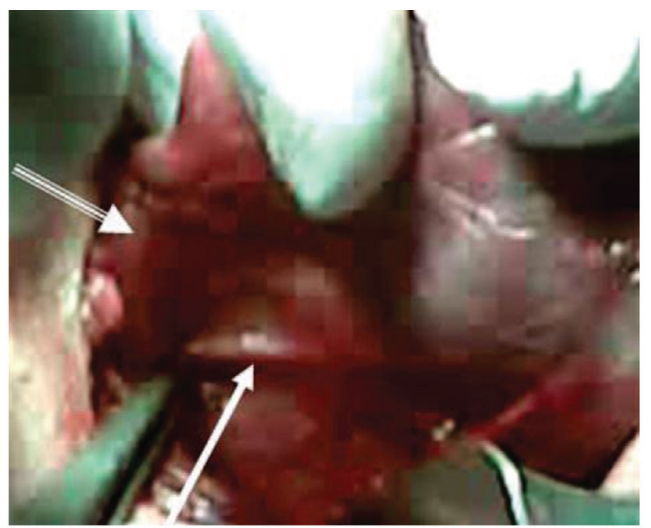

Figure 2. The external branch of the superior laryngeal nerve indentified and preserved as represented by the solid white arrow. The other arrow denoted the superior pole retracted medially. placed into the opaque envelopes and the envelopes sealed. As eligible participants were entered into the trial, these envelopes were opened in sequential order to give each patient his or her random group assignment. The envelopes were opened by the operating surgeon after patient consent and just prior to the surgery.

\section{Preoperative}

The vocal cords status for the patients was checked preoperatively by direct rigid laryngoscope (rigid laryngeal endoscope, Storz $70^{\circ}$ with video monitor was used for laryngeal evaluation) during maximum phonation and maximum inspiration (full adduction and full abduction) to ensure intact both superior laryngeal nerve (SLN) and RLN.

The preoperative preparation for thyroidectomies for the BMNG patients included the following investigations: neck ultrasound, determination of free $\mathrm{T} 3$, free $\mathrm{T} 4$, thyroid stimulating hormone and serum calcium concentration, and fine-needle aspiration cytology.

\section{Operative}

Total thyroidectomy is defined as the surgeon's attempt to perform an extracapsular removal of the entire thyroid gland including pyramidal lobe while preserving the parathyroid glands RLNs, and external branches of the SLNs. The terminal branches of the superior thyroid artery were identified and dissected meticulously as close to the thyroid capsule as possible to avoid damaging the SLN (Fig. 1). The external branch of the SLN travels inferiorly along the lateral surface of the inferior constrictor until it terminates at the cricothyroid muscle (Fig. 2). The delicate technique was performed by seeking, identifying and exposing the RLN itself with all branches, and following its course with care until it entered larynx. The main trunk of the inferior thyroid artery was preserved and the branches entering the thyroid only were cut between ligatures to preserve the blood supply of 


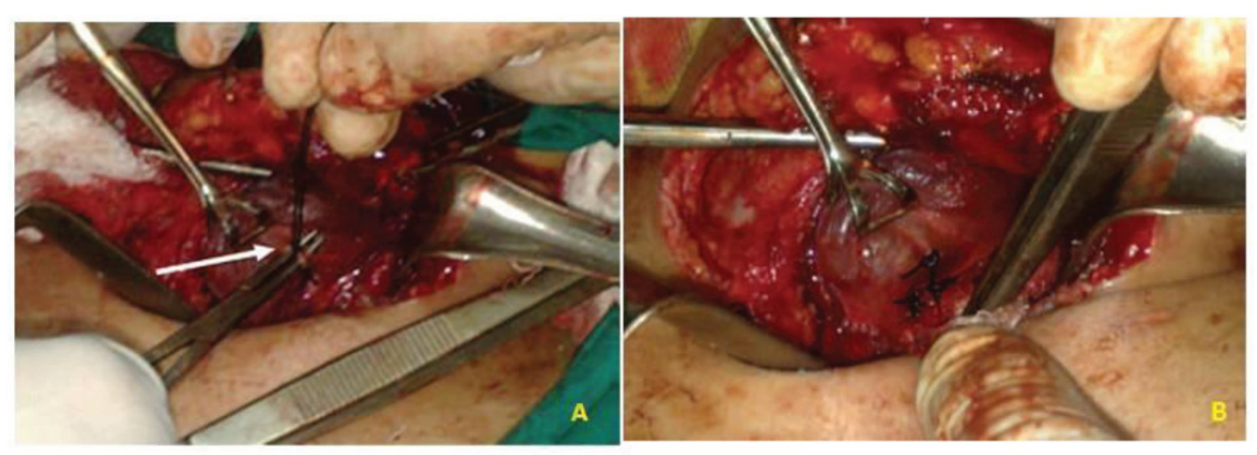

Figure 3. Branches of the inferior thyroid artery entering the thyroid $(A)$ only were cut between ligatures (B) to preserve the blood supply of the parathyroids.

the parathyroid (Fig. 3) then all the parathyroid glands were identified (Fig. 4), if possible [11]. Subtotal thyroidectomy is referred to as conservative thyroidectomy. Subtotal thyroidectomy was also carried out by the capsular dissection method, which leaves approximately 4-5 $\mathrm{g}$ of remnant tissue [1]. Figure 5 shows the specimen to be removed represented both lobes together with the isthmus. The operative field showed the thyroid bed completely free from any thyroid tissue.

\section{Postoperative periods}

\section{Status of laryngeal nerves}

The status of vocal cords was checked immediately postoperatively by laryngoscope and at the day 10 of postoperative period to assess the status of both laryngeal nerves. Temporary RLN paralysis after 6 months was considered permanent [12]. Clinical evidence of SLN injury was considered as breathy voice or diminished vocal frequency range, especially with regard to raising pitch. Using direct laryngoscope, signs of bowing, and inferior displacement of the affected cord on examination were diagnostic [13].

\section{Parathyroid status}

The function of parathyroid was checked immediately in the postoperative period by serum calcium concentration and parathyroid hormone level. Postoperative hypocalcaemia was considered when calcium level was lower than 8.0 $\mathrm{mg} / \mathrm{dL}$ (reference range $8.2-10.2 \mathrm{mg} / \mathrm{dL}$ ). Temporary hypocalcemia was defined as a calcium level lower than 8.0 $\mathrm{mg} / \mathrm{dL}$ in at least two consecutive samples (twice daily for 3 days). In these patients, hypocalcemia resolved within days. Conversely, in patients who were symptomatic and required vitamin $\mathrm{D}$ with or without calcium supplementation, we considered temporary hypocalcemia to be severe when calcium levels remained lower than $8.0 \mathrm{mg} / \mathrm{dL}$ for more than 3 days. In these patients, hypocalcemia resolved within 6 months. In patients who required vitamin $\mathrm{D}$ and calcium supplementa- tion for more than 6 months, we considered hypoparathyroidism to be permanent [12].

\section{Statistical analysis}

Data collected were processed using SPSS version 15 (SPSS Inc., Chicago, IL, USA). Quantitative data were expressed as means $\pm \mathrm{SD}$ while qualitative data were expressed as numbers and percentages $(\%)$.

\section{Ethical considerations}

Written consent was obtained from all patients or first-degree relatives before the management procedure. The local ethics committee approved the study.

\section{Results}

A total of 242 thyroidectomies were performed, with 121 in each group of total and subtotal techniques, there were 74 men $(30.6 \%)$ and 168 women $(69.4 \%)$ with a mean \pm SD age of $43.9 \pm 3.1$ years. The mean \pm SD time of hospitalization

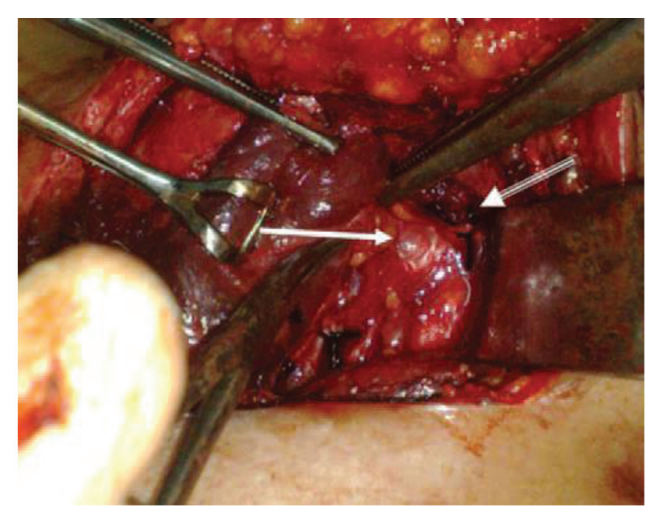

Figure 4. Two of the parathyroid glands were identified and preserved. 

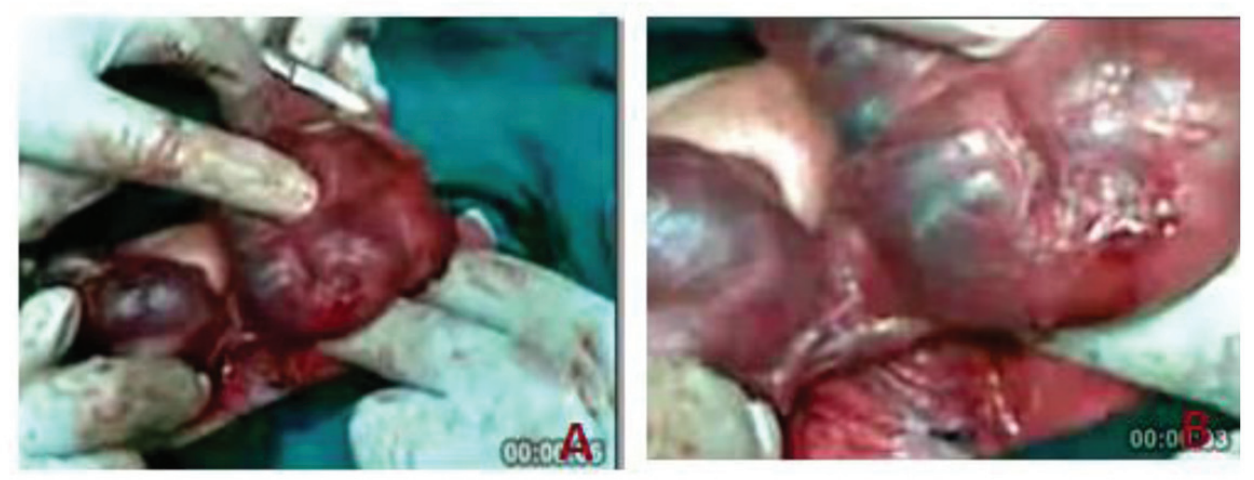

Figure 5. The specimen to be removed represented both lobes together with the isthmus (A). The operative field showed the thyroid bed completely free from any thyroid tissue (B).

was $2.1 \pm 0.9$ days. The mean weight of the excised thyroid specimens was $47.8 \mathrm{~g}$.

There was no statistical significant difference between the two groups regarding age, sex, operative time and weight of the excised tissue.

The three major complications were seen with different percentages in the two types of operations whether subtotal thyroidectomy or total thyroidectomy.

The postoperative hemorrhage and hematoma formation that needed surgical evacuation were seen in three patients $(2.5 \%)$ in ST group while four patients $(3.3 \%)$ in $\mathrm{T}$ group with insignificant statistical difference $(\mathrm{P} \geq 0.05)$. Both RLNs in all patients of both groups were successfully identified while external branch of SLN was identified in 119/121 poles $(98.3 \%)$ in ST group and in 120/121 poles (99.1\%) in T group with insignificant statistical difference $(\mathrm{P} \geq 0.05)$. No permanent or bilateral RLN injuries occurred for patients in both groups. SLN injury and temporary RLN injuries were in six patients (5\%) in ST group while in seven patients in $\mathrm{T}$ group $(5.8 \%)$ with insignificant statistical difference $(\mathrm{P} \geq$ $0.05)$ as seen in Table 1.

Both calcium level and the parathyroid hormone serum level in all patients were checked immediately in the postoperative period. No permanent hypoparathyroidism was seen in group ST patients but in one patient $(0.8 \%)$ of group $\mathrm{T}$; transient hypoparathyroidism occurred in two patients $(1.6 \%)$ of ST group and in one patient $(0.8 \%)$ in T group that improved on medications after 3 months with insignificant statistical difference $(\mathrm{P} \geq 0.05)$ as shown in Table 2 .

\section{Discussion}

Mortality rate from thyroid surgery during the 1800s was approximately $40 \%$. Most deaths were caused by infection and hemorrhage but nowadays the incidence of death ranges from zero to $0.5 \%[8,14,15]$. Thyroid surgery in recent years is generally considered quite safe owing to better preoperative preparation and proper surgical techniques that kept complications at a minimum to less than 2-3\% [16].

The extent of thyroidectomy in the management of thyroid diseases is a disputed issue among researchers and there is still no consensus as to how much thyroid tissue should be left behind [17]. Subtotal thyroidectomy has been the gold standard for patients with benign thyroid diseases. The proponents of this technique suggest that leaving a small remnant of functional gland results in euthyroidism without the need for replacement therapy and subtotal thyroidectomy is

Table 1. Recurrent Laryngeal and Superior Laryngeal Nerves Injury in Both Groups

\begin{tabular}{llllll}
\hline Group & Permanent RLN injury & Temporary RLN injury & SLN injury & Total & P value \\
\hline $\mathrm{ST}(\mathrm{N}=121)$ & 0 & $3(2.5 \%)$ & $3(2.5 \%)$ & $6(5 \%)$ & $\mathrm{NS}$ \\
$\mathrm{T}(\mathrm{N}=121)$ & 0 & $4(3.3 \%)$ & $3(2.5 \%)$ & $7(5.8 \%)$ & $\mathrm{NS}$ \\
\hline
\end{tabular}

NS: not significant. 
Table 2. Permanent and Transient Hypoparathyroidism in Both Groups

\begin{tabular}{llll}
\hline Group & Permanent hypoparathyroidism & Transient hypoparathyroidism & P value \\
\hline $\mathrm{ST}(\mathrm{N}=121)$ & 0 & $2(1.6 \%)$ & $\mathrm{NS}$ \\
$\mathrm{T}(\mathrm{N}=121)$ & $1(0.8 \%)$ & $1(0.8 \%)$ & $\mathrm{NS}$ \\
\hline
\end{tabular}

NS: not significant.

associated with a lower risk of damaging the RLNs and the parathyroid glands $[18,19]$.

Total thyroidectomy has demonstrated better control of thyroid disease with even comparable morbidity to subtotal thyroidectomy. Moreover due to these encouraging reports, total thyroidectomy has gained acceptance among surgeons of our institution $[20,21]$ and over the last few years it has rapidly displaced the more conservative surgical approaches $[6,11,12,17-19,22-24]$.

Our study showed that postoperative hemorrhage and hematoma formation were seen in three patients $(2.5 \%)$ in ST group while four patients (3.3\%) in T group with insignificance statistical difference that came in concordance with many reports. The rate of postoperative hemorrhage varied from $0.56 \%$ to $1.1 \%$ in many series $[9,14,16,24-26]$ while others described their experiences of thyroidectomies with hemorrhage up to $2.5 \%$ [27].

In our study SLN and temporary RLN injuries were seen in six patients (5\%) in ST group while in seven patients in T group $(5.8 \%)$ with insignificance statistical difference.

Previous studies of same interest reported that the frequency of RLN injury ranges from $0.5 \%$ to $5 \%$ in different thyroid surgery centers and increases in case of both recurrent goiter and total thyroidectomy due to thyroid cancer. The nerve lesion varies from irreversible, persistent and transient dysfunction with good prognosis of complete recovery from several weeks to 2 years [28-30].

In the light of law and medical aspects it was suggest obligatory laryngological examination with the evaluation of vocal cords mobility before surgery and on the third postoperative day in order to identify early RLN lesion. Permanent RLN paralysis may be diagnosed on the basis of multiple laryngological examinations in the period between 3 and 24 months after surgery [29].

Our study showed that no permanent hypoparathyroidism was seen in group ST patients but in one patient $(0.8 \%)$ of group $\mathrm{T}$; transient hypoparathyroidism occurred in two patient (1.6\%) of ST group and also one patient $(0.8 \%)$ in T group. The incidence of hypocalcemia depends on the type of surgery performed. Two independent papers reported that after thyroidectomy for large multinodular goiter, tempo- rary hypocalcemia requiring calcium replacement occurred in $20 \%$ of patients. This usually occurs about $36 \mathrm{~h}$ postoperatively. Only up to $3 \%$ of patients remained permanently hypocalcemic $[7,31,32]$. Another study reported postoperative hypocalcemia with rate of $4.7 \%$ that persistent in $1.3 \%$ [4]. Chronic hypoparathyroidism with unrecovering normal function after 6 months was $1.4 \%$ and seen in more extensive surgery. If the cost of surgery for thyroid nodules is low $0 \%$ of chronic hypoparathyroidism was obtained [33, 34].

\section{Conclusion}

Total or subtotal thyroidectomy outcomes and complications are similar depending on good and proper preoperative preparation and the use of a meticulous surgical technique can reduce the incidence of postoperative complications in thyroid surgery. Experienced surgeons with careful observation of his patients before discharge are needed to reduce these complications.

\section{Disclosures}

The authors declare they have neither financial disclosures nor conflict of interest.

\section{References}

1. Karamanakos SN, Markou KB, Panagopoulos K, Karavias D, Vagianos CE, Scopa CD, Fotopoulou V, et al. Complications and risk factors related to the extent of surgery in thyroidectomy. Results from 2,043 procedures. Hormones (Athens). 2010;9(4):318-325.

2. Laurberg $\mathrm{P}$, Nohr SB, Pedersen KM, Hreidarsson AB, Andersen S, Bulow Pedersen I, Knudsen N, et al. Thyroid disorders in mild iodine deficiency. Thyroid. 2000;10(11):951-963.

3. Tunbridge WM, Evered DC, Hall R, Appleton D, Brewis M, Clark F, Evans JG, et al. The spectrum of thyroid disease in a community: the Whickham survey. Clin En- 
docrinol (Oxf). 1977;7(6):481-493.

4. Ozbas S, Kocak S, Aydintug S, Cakmak A, Demirkiran MA, Wishart GC. Comparison of the complications of subtotal, near total and total thyroidectomy in the surgical management of multinodular goitre. Endocr J. 2005;52(2):199-205.

5. Acun Z, Comert M, Cihan A, Ulukent SC, Ucan B, Cakmak GK. Near-total thyroidectomy could be the best treatment for thyroid disease in endemic regions. Arch Surg. 2004;139(4):444-447; discussion 447.

6. Ku CF, Lo CY, Chan WF, Kung AW, Lam KS. Total thyroidectomy replaces subtotal thyroidectomy as the preferred surgical treatment for Graves' disease. ANZ J Surg. 2005;75(7):528-531.

7. Farling PA. Thyroid disease. Br JAnaesth. 2000;85(1):1528.

8. Dener C. Complication rates after operations for benign thyroid disease. Acta Otolaryngol. 2002;122(6):679683.

9. Benzarti S, Miled I, Bassoumi T, Ben Mrad B, Akkari $\mathrm{K}$, Bacha O, Chebbi MK. [Thyroid surgery (356 cases): risks and complications]. Rev Laryngol Otol Rhinol (Bord). 2002;123(1):33-37.

10. Aly H. Post Thyroidectomy Hypocalcaemia. Egy J Surg. 2008;27(1):41-47.

11. Christou N, Mathonnet M. Complications after total thyroidectomy. J Visc Surg. 2013;150(4):249-256.

12. Efremidou EI, Papageorgiou MS, Liratzopoulos N, Manolas KJ. The efficacy and safety of total thyroidectomy in the management of benign thyroid disease: a review of 932 cases. Can J Surg. 2009;52(1):39-44.

13. Friedman M, LoSavio P, Ibrahim H. Superior laryngeal nerve identification and preservation in thyroidectomy. Arch Otolaryngol Head Neck Surg. 2002;128(3):296303.

14. Ignjatovic M, Cuk V, Ozegovic A, Cerovic S, Kostic Z, Romic P. [Early complications in surgical treatment of thyroid diseases: analysis of 2100 patients]. Acta Chir Iugosl. 2003;50(3):155-175.

15. Bhansali SK, Chandalia HB. Thyrotoxicosis--surgical management in the era of evidence-based medicine: experience in western India with 752 cases. Asian J Surg. 2002;25(4):291-299.

16. Savargaonkar AP. Post-thyroidectomy haematoma causing total airway obstruction - A Case Report. Indian J Anaesth. 2004;48(6):483-485.

17. Melliere D, Etienne G, Becquemin JP. Operation for hyperthyroidism. Methods and rationale. Am J Surg. 1988;155(3):395-399.

18. Wagner HE, Seiler C. Recurrent laryngeal nerve palsy after thyroid gland surgery. Br J Surg. 1994;81(2):226228.

19. Lasagna B, Resegotti A, De Paolis P, Balbo G. [Exten- sion of thyroidectomy in the treatment of benign nodular thyroid diseases]. Minerva Chir. 1993;48(23-24):14211424.

20. Saber A, Rifaat M, Ellabban G, Gad MA. Total Thyroidectomy by Loupe Magnification: A Comparative Study. European surgery. 2011;43(1):49-54.

21. Farahat FY, Hegazy NI, Saber A. Post-thyroidectomy complications: a surgical malpractice. Zag U Med J. 2005;18(4):458-465.

22. Razack MS, Lore JM, Jr., Lippes HA, Schaefer DP, Rassael H. Total thyroidectomy for Graves' disease. Head Neck. 1997;19(5):378-383.

23. Barakate MS, Agarwal G, Reeve TS, Barraclough B, Robinson B, Delbridge LW. Total thyroidectomy is now the preferred option for the surgical management of Graves' disease. ANZ J Surg. 2002;72(5):321-324.

24. Musholt TJ. [Total thyroidectomy for multinodular goiter]. Chirurg. 2010;81(7):603-606, 608-611.

25. Cichon S, Anielski R, Orlicki P, Krzesiwo-Stempak K. [Post-thyroidectomy hemorrhage]. Przegl Lek. 2002;59(7):489-492.

26. Chen WJ, Deng Y, Liang ZY. [Acute respiratory tract obstruction during thyroid operation: analysis of 10 cases]. Di Yi Jun Yi Da Xue Xue Bao. 2003;23(5):507, 509.

27. Agarwal A, Mishra SK. Post-thyroidectomy haemorrhage: an analysis of critical factors in successful management. J Indian Med Assoc. 1997;95(7):418-419, 433.

28. Chiang FY, Lee KW, Huang YF, Wang LF, Kuo WR. Risk of vocal palsy after thyroidectomy with identification of the recurrent laryngeal nerve. Kaohsiung J Med Sci. 2004;20(9):431-436.

29. Jamski J, Jamska A, Graca M, Barczynski M, Wlodyka J. [Recurrent laryngeal nerve injury following thyroid surgery]. Przegl Lek. 2004;61(1):13-16.

30. Otto RA, Cochran CS. Sensitivity and specificity of intraoperative recurrent laryngeal nerve stimulation in predicting postoperative nerve paralysis. Ann Otol Rhinol Laryngol. 2002;111(11):1005-1007.

31. Robertson ML, Steward DL, Gluckman JL, Welge J. Continuous laryngeal nerve integrity monitoring during thyroidectomy: does it reduce risk of injury? Otolaryngol Head Neck Surg. 2004;131(5):596-600.

32. Trupka A, Sienel W. [Autotransplantation of at least one parathyroid gland during thyroidectomy in benign thyroid disease minimizes the risk of permanent hypoparathyroidism]. Zentralbl Chir. 2002;127(5):439-442.

33. Safioleas M, Stamatakos M, Rompoti N, Mouzopoulos G, Iannescu R, Salichou V, Skandalakis P. Complications of thyroid surgery. Chirurgia (Bucur). 2006;101(6):571581.

34. Glinoer D, Andry G, Chantrain G, Samil N. Clinical aspects of early and late hypocalcaemia afterthyroid surgery. Eur J Surg Oncol. 2000;26(6):571-577. 